\title{
A Study on Consumer Behavior towards Fmcg Products among the Rural- Suburban Hhs of Ernakulam
}

Kumar NA ${ }^{1 *}$ and Joseph $\mathrm{J}^{2}$

${ }^{1}$ Research Scholar, Department of Commerce \& Business Management, Karpagam University, Coimbatore, India

${ }^{2}$ Former Dean, Department of Commerce\& Business Management, Karpagam University, Coimbatore, India

\begin{abstract}
The rural consumers are known to earn low income, have low level of literacy, low level of brand awareness, asymmetric information, inadequate communication and transportation facilities. The Rural markets and sub-urban markets are now expanding in Kerala with ever greater penetration index, as the growth seems stunted in the urban markets. In this study, Rural \& suburban areas of Ernakulam with a sample size of 100 respondents. The study intends to identify the level of influence of various factors on the purchase of FMCG products-soaps \& detergents among the rural/ semi urban consumers. The study emphasized that rural consumers gave more importance to the 'quality' of the FMCG-personal care brands they bought rather than the normative influences or social appeal vide celebrity endorsements in the mass media.
\end{abstract}

Keywords: Consumer behavior; Demographics; Rural consumer; FMCG Products; SED; Attitude

\section{Introduction}

India is dichotomous with both rural and urban market structure. The urban markets have reached saturation in market penetration and very high competition between marketers of $\mathrm{HH}$ goods prevail. The urban markets are today an oasis for the marketers to fetch profits in view of the high awareness and refined tastes of the consumers as well. In contrast, the rural markets are greener pastures for any marketer in view of the high growth and untapped potential. Rural market population has higher income and competes with their urban counter parts today which lead to higher demand. The literacy level and job opportunities especially in the I.T sector is on the increase through technology parks and info parks located in rural hamlets of Kerala. The higher infrastructure development by way of new roads and bridges, drainage, drinking water and health programs of the government has improved the logistics in the rural areas. Today the trend in Kerala is reverse migration from the urban areas to the rural areas for peaceful living due to large-scale developments achieved in the communication, automobiles, branded goods preference and increased affordability for the consumers. The growing developments in rail and road commuting for the passengers has added mobility to rural consumers of other districts of Ernakulam as well to reside in rural/suburban areas and travel to/from workplaces. These consumers having lived/worked or commuted to urban areas of Ernakulam have developed higher level of awareness and with greater aspiration to match with the urbanites in consumption. The marketers have improved their distribution and service logistics with franchisees and dealer outlets, as also improved their product penetration levels among the rural masses through the mass media specifically the Internet and CTV. Though the spatial distribution is larger with lower density of population, the market mix strategies of leading FMCG brands are attuned to the specific sociocultural needs and preferences like the popular segment as well as premium segment in product portfolio management. This CB study explains the attributes and relevant aspects.

\section{Literature Review}

\section{FMCG scenario}

The term FMCG (fast moving consumer goods), although popular and frequently used does not have a standard definition and is generally used in India to refer to products of everyday use. Conceptually, however, the term refers to relatively fast moving items that are used directly by the consumer. The Indian FMCG sector has a market size of US\$ 13.1 billion and is the fourth largest sector in the Indian economy. A well-established distribution network, mature logistics, intense competition between the organized and unorganized segments, National brands and private labels/local brands characterize the sector. It has been estimated that FMCG sector sales in India is likely to increase from Rs. 92,100 cores in 2011-12, to over Rs.1,30,000 cores in 2015 . With the presence of $12.2 \%$ of the world population in the villages of India, the Indian rural FMCG market is formidable indeed. The Indian rural market has more than 700 Million Consumers (70\% of the Indian population) and accounts for $50 \%$ of the total FMCG market. The Personal care category in India was valued at Rs. 54.6 billion. An average Indian spends $8 \%$ of his income on personal care products. Personal care mainly consists of Hair Care Skin Care, Oral Care, Personal Wash (Soaps), Cosmetic and Toiletries, Feminine Hygiene. The sales of FMCG Personal care segment is growing by leaps and bounds in Kerala, with the most literate and trans-culture embracing consumers in India. Kerala has been witnessing a social transformation over the past decade to form a modern consumerist state with little focus on farming sector, increased interest in I.T related parks, educational services, medical facilities and tourism, higher income with huge remittances from the NRI's and increased living standards even in the rural areas providing better growth prospects and demand for the FMCG sector. The per capita consumption of FMCG products is on the rise, thanks to the consumer acculturation. The deeper market penetration and positioning of FMCG brands catering

*Corresponding author: Kumar NA, Research Scholar, Department of Commerce \& Business Management, Karpagam University, Coimbatore, India, Tel: 09447986364; E-mail: aniln@factltd.com

Received November 06, 2014; Accepted November 11, 2014; Published November 18, 2014

Citation: Kumar NA, Joseph J (2014) A Study on Consumer Behavior towards Fmcg Products among the Rural-Suburban Hhs of Ernakulam. J Glob Econ 2: 127. doi:10.4172/2375-4389.1000127

Copyright: (c) 2014 Kumar NA, et al. This is an open-access article distributed under the terms of the Creative Commons Attribution License, which permits unrestricted use, distribution, and reproduction in any medium, provided the original author and source are credited. 
to the rising living standards and modern values of the rural consumer along with better infrastructure facilities by way of mobile and internet communication, roads and rail connectivity fosters higher acceptance and sales of FMCG products in the rural areas of Ernakulam. The outflow of families from rural to the urban population of Kochi has been on the rise in search for better jobs/career, and the current trend has been that most urban people are settling down in the rural areas for pure habitat and peaceful living. Currently, urban India accounts for $66 \%$ of total FMCG consumption, with rural India accounting for the remaining $34 \%$. However, rural India accounts for more than $40 \%$ consumption in major FMCG categories such as personal care, fabric care, and hot beverages. Among the packaged food segment, it is estimated that processed foods, bakery, and dairy have long-term growth potential in Kerala in both rural and urban areas due to dependence on neighboring states. An average Indian spends $8 \%$ of his income on personal care products like Hair Care, Skin Care, Oral Care, Personal Wash (Soaps), Cosmetic and Toiletries, Feminine Hygiene, Shampoo, Hair Dye etc. Today the Personal care products, except those in oral care category, are seldom regarded as luxury items. Both premium and popular segments in the FMCG products are positioned catering the income class of the rural consumers as well. With the increase in rural income and improvements in infrastructure-roads \& bridges network product the penetration levels have increased substantially. Since the consumption level in urban areas is already high in most of the categories, the growth can come only from deeper penetration and higher consumption in rural areas. The FMCG Products have specific characteristic like small value, but forms a significant part of the consumer's family budget, limited inventory of these products is maintained by consumer and prefers to purchase them frequently, as and when required, most products are perishable/limited shelf life, the consumer spends little time on the purchase decisions being habitual with high brand loyalty, Brand recommendations of reliable retailer/dealer drive purchase decisions are accepted, Trial of a new product i.e. brand switching is often induced by heavy advertisement, recommendation of the retailer or neighbors/friends, FMCG products cater to necessities, comforts as well as luxuries, and caters to entire consumer lot with Price and income elasticity of demand varying across products and consumers. A plethora of studies in rural segment on FMCG exist, the most recent ones are cited herein. Garga et al. [1] observed that in Punjab, majority of rural respondent's preferred FMCG products in medium package sizes at medium price range and wanted more value for money products. Selvaraj [2] in his research regarding rural consumer behavior observed that 'nearness' was the most significant factor influencing their purchase of the non-durables. It was seen that high price was another important bottleneck for the rural consumers. Anandan et al. [3] observed that the quality was the major driver to prefer a particular brand in washing soaps in the rural market, and when preferred brands were not available, customers bought the available brands. Also high price and non-availability were the key reasons for dissatisfaction among the rural consumers. Madhavi et al. [4] reported that most of the rural consumers were influenced by quality of the product followed by price. Value for money products had a better acceptance for rural market penetration. Generic products with intensive advertisement campaigns were recommended to attract non-users of the product. Nagaraja [5] investigated the impact of socio-economic influences on rural consumer behavior in terms of their buying practices, to the social status and level of income, and revealed that rural consumer was more rational as a buyer and exhibited a higher level of rationality compared to the urban consumer. Rural consumer tried for better value for money spent in the purchase of FMCG products; easy availability, Price and Quality were the influential factors cited.

\section{Consumer motive}

Consumer motive relates to a wide spectrum of wants and needs. Consumer motivation is an internal state that drives people to identify and buy products or services that fulfill conscious and unconscious needs or desires. The fulfillment of those needs can then motivate them to make a repeat purchase or to find different goods and services to better fulfill those needs. Needs could be positive, negative, utilitarian or hedonic, conscious or unconscious, and accordingly goals are formulated. A person has many goals and these goals are never ending and a failure to satisfy them sometimes leads to frustration. A person can deal with this by targeting substitute or related goals or by building a defense mechanism such as aggression, rationalization, regression and withdrawal. A need becomes a motive when it is aroused to a sufficient level of intensity. A motive is a need that is sufficiently pressing to drive the person to act. Needs can be classified into biogenic and psychogenic needs. Biogenic needs arise from psychological states of tension such as hunger, thirst or discomfort while psychogenic needs arise from psychological states of tension such as the need for recognition, esteem or belonging. Motivation strengthens the ambition, increases initiative and gives direction, courage, energy and the persistence to follow one's goals. A motivated person takes action and does whatever he/she needs to achieve his/her goals. Motivation is usually strong, when one has a vision, a clear mental image of a certain situation or achievement, and also a strong desire to materialize it. In this case motivation pushes one forward, toward taking action and making the vision a reality. Motivation can be applied to every action and goal. Motivation is present whenever there is a clear vision, precise knowledge of what one wants to do, a strong desire and faith in one's abilities. Human beings have wants and desires which influence their behavior. Only unsatisfied needs influence behavior, satisfied needs do not. Since needs are many, they are arranged in order of importance, from the basic to the complex. The person advances to the next level of needs only after the lower level need is at least minimally satisfied. These needs play an important role in influencing consumer behavior. Motivational conflict is a concept which deals with the conflicting motives of the customers. The level of involvement (how interested the consumer was about a product) determines the degree of motivation a consumer had to buy that product. The source of stimulation and the particular situation the consumer is in when he or she comes into contact with the product also determine the level of involvement.

The marketer who understands the various needs that motivate a consumer in purchasing a product or service and is able to design and showcase his products accordingly will be successful. Buying motives determine two things: what consumers want to do, and how much they want to do it. To market successfully, purchase motives first have to be directed towards products. Second, the drive has to be strong enough so that consumer will act on it; have to be willing to pay the price in terms of money, time, and effort. A motive is an internal energizing force that orients a person's activities toward satisfying a need or achieving a goal. Actions are effected by a set of motives, not just one. If marketers can identify motives then they can better develop a marketing mix. Motives often operate at a subconscious level therefore are difficult to measure. The consumer might decide to buy something based on which goods or services most closely meet and satisfy motivational wants and needs. Marketers aim to gain the most impact and eventual sales by linking their products and services to clearly defined consumer needs and by understanding what motivates people to buy. Motives give direction to human behavior. A motive is an inner state that energizes, activates, or moves and directs or channels behavior towards the goal. Motivation can be either positive or negative. A positive motivation happens 
when an individual experiences a driving force towards an object or person or situation. On the other hand, a driving force compelling the person to move away from someone or something will be known as negative motivation. Moods are emotions felt less intensely and are short-lived. Marketing stimuli can induce positive or negative moods. Theories of personality based upon needs and motives suggest that our personalities are a reflection of behaviors controlled by needs. While some needs are temporary and changing, other needs are more deeply seated in our nature. According to Murray, these psychogenic needs function mostly on the unconscious level, but play a major role in our personality. The Psychogenic needs are Ambition Needs, materialistic Needs, Power Needs, Affection Needs and Information Needs. Murray also believed that environmental factors play a role in how these psychogenic needs are displayed in behavior. Each need is important in and of itself, but Murray believed that needs can be interrelated, can support other needs, and can conflict with other needs. According to Duncan consumer motive is defined as "internal impulses that when simulated initiate some type of response." Consumers are continuously reacting to their internal impulses as well as the external environment. Since internal impulses and the external environment also interact, resulting in psychological motivations to fulfill needs and wants, Kim and Jin argue that consumer motives are known to be the drivers of behavior that bring consumers to the retail store. Based on past research, consumer motives can be categorized from four perspectives. Firstly, the social influences on consumer motives such as the culture, sub-culture, social class, reference groups and families. Secondly, the situational influences on consumer motives such as physical features, social features, time, task features and current conditions. Thirdly, psychological influences on consumer motives include product knowledge and product involvement. Finally, the marketing mix influences on consumer motives such as product, price, promotion and place. Price is the main motive in buying as illustrated by Belch [6]. Morschett show that the influence of shopping motive has a much more profound effect on the attitude towards retail stores than towards perception of store attributes. Product-related considerations (eg. assortment and quality) and pricing appear to be the most critical aspects of consumer motives. Bijapurkar [7] indicates that knowledge is located between past achievements and future promise. It is not enough to promote a product as filling a functional need, it has to touch the consumer on a deeper level that evokes identification with the product. The consumer needs to feel that they are somehow linked to the product, and that it produces a favorable image of them and who they want to be. This will motivate the consumer to buy, and keep buying a product. The consumer is the face of a product. When a human is missing everything in life, he is highly motivated by physiological needs than any other. If the physiological needs are satisfied, a new set of needs emerges. At the safety needs level, one is motivated by security, stability, dependency and protection. When there are real threats to law and authority, safety needs become quite urgent on the social scene. Human beings will tend to respond to danger with realistic regression and will prepare to defend themselves. Once this level has been satisfied, the belongingness and love need arrives. Man's desire for fulfillment is only possible if the individual is doing what he is fitted for. Buying motive is a strong desire/feeling or urge from within, a drive/stimulus/emotion which plays major role in influencing the consumer attitude and purchase decision. Buying motives could be product oriented or patronage oriented, of rational/emotional type.

The various functions of attitude lead to the consumer's overall attitude toward engaging in the given purchase decision, thus influencing behavioral intention [8]. The attitude toward the behavior or action reveals the consumer's inclusive evaluation of engaging in the behavior. Behavioral intention reflects the consumer's plan of action or a proposition associating one's self with a future consumption action or behavior Peter [9]. Consumers compare various brands/ products that are in their evoked/consideration set. The consumer evaluates alternatives in terms of functional \& psychological benefits that they offer and the product attributes are most important. The basic underlying psychological process associated with alternative evaluation stage is the attitude formation. Attitudes are learnt predispositions towards an object/product. The multi-attribute attitude model explains how consumer evaluates alternatives on a range of attributes. Information is integrated and decisions rules are made by the consumer. The consumer evaluates alternatives on the salient/ important attributes and makes their buying decision. The consumer motive drives the consumer to form an attitude which in turn leads to the purchase intention resulting in an actual purchase act.

\section{Consumer attitude}

Consumer attitude towards a product is learned, either directly through self - experience with the consumption of a product or its service, or indirectly through receiving external information about the product or its service. The second is that attitude is an antecedent to behavior. Therefore, it becomes essential to know about the way information is received and the manner in which it is processed, and the nature of the messages obtained. Attitudes refer to what a person feels/believes about something. Attitudes may be reflected in how an individual acts based on his/her beliefs. Once formed, attitudes are very difficult to change. However, increased awareness/information through deliberate advertising appeal/persuasion can change an attitude. Consumers are living bundles of needs. All behavior takes place in a social setting which is unique to that individual. Influential social group members establish role expectations. Most attitudes a consumer possess are stored according to the various roles one performs. A great portion of the attitudes consists of the role expectations that have been learned. The consumer role behavior is enacted to satisfy wants/ needs of the consumer. The pattern of consumer's behavior differ at different points in his/her life. Also the consumer's behavior at any point of time is influenced by any past behavior. Consumer's behavior patterns change with certain events in one's life. The consumer role provides a means by which a person may express himself/herself. The strength of the attitude moderates the influence of attitudes on thoughts and behavior. Attitude is relatively enduring evaluation of products/ideas. To the extent that a consumer evaluates a product positively, that consumer is more likely to consume/use the product. Attitudes are presumed to guide behavior. A strongly held attitude is the result of relatively effortful cognitive elaboration. Elaboration occurs when consumer possess the motivation and ability to scrutinize information to form/change an attitude based on the thoughts held in response to information about a product Attitudes could be formed or affected by both the tangible as well as intangible attributes of a product. The emotional element of attitude is influenced by personal experience, personality and sensual perceptions. Emotional reaction is a principal aspect for the attitude formation and change. The behavior of consumers is defined by feelings that stipulate convictions forming attitude. Attitudes are complex, and the set of beliefs \& evaluations combination predicts the overall attitude of the consumer. Attitudes formed by direct personal experience are stronger and more predictive of behavior than those formed indirectly through persuasion/Ads. Depending on the consumer's level of involvement and the situations, attitudes can result from other hierarchies of effects. Motivation through emotion alone results in an attitude change. Real attitude change happens only through the central cognitive processing route (high level 
of involvement) in contrast to the peripheral/affective processing route (low level of involvement) based on cues/feelings. The route selection is as mentioned above, based on the motivation and evaluation capability factors of the consumer. Attitudes formed in high involvement are stronger, consistent/stable over a longer period, resistant to persuasion and predictive of behavior. The consumer behavior is the transmission of purchase intention to actual action. In contrast, the attitudes are made up of the beliefs that a person accumulates over time. Beliefs are formed from direct experience, outside information, from others and also selfgenerated. Only the salient product related beliefs actually influence the attitude of the consumer; attitude is the sum of the products of salient beliefs and evaluation thereof. (Attitude towards the object model of Fishbein). However, in the Multi-attribute model, consumers with high involvement combine their beliefs about product attributes to form attitude about the product. Attitudes predict behavior owing to factors like higher involvement, motive, brands/products benefits and attitude strength.

\section{Consumer behavior}

The decision making of the consumer is determined by the pre purchase behavior, which is preceded by the intention to buy/consume and a host of other antecedent factors. Some of these factors are intrinsic to the consumer like the personal aspects -beliefs/evaluation based attitude towards the act(purchase), while the extrinsic variables like social aspects- subjective norms and the perceived /actual behavioral control etc., conditioned within the situational construct, influence the consumer's behavioral intention. Attitude-behavior consistency has been of great interest to researchers since the 1930s. In the early 1970s, a number of researchers [10] developed attitude-behavior models that focused on the causal relationship between attitudes and behavior. According to Kashyap [11], behavior is a function of behavioral intentions, which are themselves a function of attitudes and subjective norms. The Theory of Reasoned Action stipulates that beliefs underlie a person's attitudes and subjective norms, which ultimately determine intentions and behavior [12]. Researchers have drawn on attitude-behavior relationship, namely the theory of planned behavior, to explain consumer behavior. The extrinsic aspects also condition the attitude dimension, and the attitude functions (consumption motive) thus influencing the final purchase decision of the consumer. The purchasing decision of the consumer is an individual one [13] and the complexity of the decision depends on the consumer's degree of information search, the evaluation of alternatives and the choice of products [14]. The consumer decision-making process is a sequential and repetitive series of psychological and physical activities ranging from problem recognition to post-purchase behavior. Marketdominated variables (such as the environment and advertising) and consumer-dominated variables (such as needs, motives, personality and perception) simultaneously interact to influence the consumer's purchasing decision.

\section{Objectives of the study}

- To analyze key aspects, product attributes media, sales promotion \& $\mathrm{HH}$ expenditure moderating the purchase attitude-behavior of Rural-Suburban $\mathrm{HH}$.

- To find the influence of SED (Socioeconomic demographic) of consumers on purchase behavior and any difference between Hus-Wife and Rural-Suburban respondents.

- Examine influence of buying motive and attitude on the purchase behavior.
- Understand the significant attributes of shops influencing the purchase behavior.

- Find the most preferred and rank the top six brands with salient attributes.

\section{Null hypothesis formulation}

H01: There is no significant influence of various consumer attitude enablers of FMCG products on the purchase behavior of rural consumers

H02: There is no significant influence of purchase attitude on the purchase behavior of rural consumers.

H03: There is no significant influence of SED factors on the purchase behavior of rural consumers.

H04: There is no significant difference between wife and husbands on the enablers of purchase behavior.

H05: There is no significant difference in the influence of aspects on the purchase behavior of rural and semi-urban consumers.

\section{Research Methodology}

The study was a descriptive research design. The study area included 10 rural villages/suburban pockets of Ernakulam District. The population size of Ernakulam district is 38 lakh persons with 8.4 lakh HHs, of which the rural areas account for about 4.6 lakh HHs. The sampling method used was random Sampling on 50 rural respondents spread across ten remote villages and 50 semi urban respondents spread across the outskirts of major ten towns of Ernakulam considered for the study. The primary data collection tool applied was Interview Schedule based HH primary market survey conducted during 2013-14 period.

\section{Analysis}

The demographic profile of the sub urban and rural consumers is listed vide Table 1 below which is self-explanatory on the demographic variables of Rural and semi-urban HHs.

The levels of influence of various factors on rural and semi urban consumers' purchase behavior were studied with respect to FMCG personal care products vide Table 2 below.

From the Table 2 above, it is obvious that 'Quality' is the highest influencing factor with $68 \%$, followed by Purchase attitude with $67 \%$ and Brand related with 58\%. The factor 'Friends/Social Group' has the lowest influence of 59\% followed by 'Attractive packaging' as the next lowest influencing factor $23 \%$ among the rural respondents.

The Table 3 most prominent among the rural respondents is CTV and among the semi urban respondents is again CTV but closely followed by the Internet.

Among the semi urban respondents (Table 4), the top priority is for money making and spending while among the rural respondents is for welfare of family members. Notable is the higher priority accorded for imparting professional education of children among both semi urban and rural respondents.

The most popular sales promotion measure on FMCG goods opted by the respondents is the Price-off discounts among both the semi urban and rural respondents Table 5.

Vide H03, the SED aspects (Table 6) except other's opinion on the consumers significantly influence the purchase behavior of the 
Citation: Kumar NA, Joseph J (2014) A Study on Consumer Behavior towards Fmcg Products among the Rural-Suburban Hhs of Ernakulam. J Glob Econ 2: 127. doi:10.4172/2375-4389.1000127

Page 5 of 10

\begin{tabular}{|c|c|c|c|c|}
\hline S.No & Chrtcs & Variations & $\begin{array}{c}\text { Semi- } \\
\text { urban (\%) }\end{array}$ & $\begin{array}{c}\text { Rural } \\
(\%)\end{array}$ \\
\hline \multirow{4}{*}{1} & \multirow{4}{*}{ Age } & $21-30$ years & 9.21 & 9.39 \\
\hline & & 31-40years & 40.92 & 43.28 \\
\hline & & 41-50years & 35.74 & 29.65 \\
\hline & & 51-60years & 14.13 & 17.68 \\
\hline \multirow{5}{*}{2} & \multirow{5}{*}{ FLC Stages } & Full Nest I(child<10yrs) & 21.49 & 198.66 \\
\hline & & Full Nest II(child $>10 \&<18 y r s)$ & 33.86 & 28.16 \\
\hline & & Full Nest III(child >18yrs) & 24.42 & 19.85 \\
\hline & & Empty Nest & 11.84 & 18.6 \\
\hline & & Others & 8.39 & 13.73 \\
\hline \multirow{3}{*}{3} & \multirow{3}{*}{$\begin{array}{c}\text { Family Type- } \\
\text { size }\end{array}$} & Nuclear- 1 to 4 members & 66.61 & 33.13 \\
\hline & & Joint -5 to 9 members & 29.32 & 49.12 \\
\hline & & Joint-10 to 14 members & 4.07 & 17.75 \\
\hline \multirow{4}{*}{4} & \multirow{4}{*}{$\begin{array}{l}\text { Educational } \\
\text { qualifications }\end{array}$} & SSLC/School & 2.96 & 8.75 \\
\hline & & Graduation & 14.57 & 33.9 \\
\hline & & Post- Graduation & 40.6 & 35.42 \\
\hline & & Professional \& higher & 41.87 & 21.93 \\
\hline \multirow{4}{*}{5} & \multirow{4}{*}{$\begin{array}{c}\text { Professional } \\
\text { category }\end{array}$} & $\begin{array}{l}\text { Government employee/PSU/ } \\
\text { University }\end{array}$ & 36.81 & 16.57 \\
\hline & & $\begin{array}{l}\text { Private firms employment/Schools/ } \\
\text { Colleges/Clinics }\end{array}$ & 25.93 & 40.65 \\
\hline & & $\begin{array}{l}\text { Business/Law/Medical/ } \\
\text { Accountancy }\end{array}$ & 26.16 & 21.32 \\
\hline & & $\begin{array}{l}\text { Others self-employed/Agency/ } \\
\text { Broker. }\end{array}$ & 11.1 & 21.46 \\
\hline \multirow{4}{*}{6} & \multirow{4}{*}{$\begin{array}{c}\text { Disposable } \\
\text { Income of } \mathrm{HH} \\
\text { per month(Rs.) }\end{array}$} & >=Rs.0.50 Lakh & 10.13 & 8.95 \\
\hline & & Rs. $25,000 /-$ to $50,000 /-$ & 55.48 & 11.74 \\
\hline & & Rs. $15,000 /-$ to $25,000 /-$ & 25.72 & 58.48 \\
\hline & & Rs.5,000/- to $15,000 /-$ & 8.67 & 20.83 \\
\hline \multirow{4}{*}{7} & \multirow{4}{*}{$\begin{array}{c}\text { Current } \\
\text { Dwelling habitat } \\
\text { adopted }\end{array}$} & Self- owned independent house & 21.96 & 62.46 \\
\hline & & Rented independent house & 17.48 & 25.65 \\
\hline & & Self - owned Apartment/Villa & 40.84 & 6.28 \\
\hline & & Rented Apartment/Villa & 19.72 & 5.61 \\
\hline \multirow{4}{*}{8} & \multirow{4}{*}{$\begin{array}{l}\text { Religious belief } \\
\text { affiliation }\end{array}$} & Hinduism & 32.77 & 43.35 \\
\hline & & Christianity & 36.63 & 24.72 \\
\hline & & Muslim/Islam & 21.76 & 28.61 \\
\hline & & Other religious beliefs & 8.84 & 3.32 \\
\hline
\end{tabular}

Table 1: Demographics of consumers.

\begin{tabular}{|c|l|c|c|c|}
\hline SI.No & Product Attributes & $\begin{array}{c}\text { Most } \\
\text { salient } \\
\text { attributes } \\
\%\end{array}$ & $\begin{array}{c}\text { Moderately } \\
\text { salient } \\
\text { attributes } \\
\%\end{array}$ & $\begin{array}{c}\text { Least } \\
\text { salient } \\
\text { Attributes } \\
\%\end{array}$ \\
\hline $\mathbf{1}$ & Quality-Value for money & 68 & 21 & 11 \\
\hline $\mathbf{2}$ & Attractive Packaging size & 48 & 29 & 23 \\
\hline $\mathbf{3}$ & $\begin{array}{l}\text { Brands image- availability } \\
\text { \& credibility with celebrity } \\
\text { endorsements }\end{array}$ & 58 & 24 & 18 \\
\hline $\mathbf{4}$ & Pricing-affordability & 64 & 20 & 16 \\
\hline $\mathbf{5}$ & Retailor patronage & 44 & 42 & 14 \\
\hline $\mathbf{6}$ & $\begin{array}{l}\text { Product attributes like Fragrance, } \\
\text { healthy and safer, antiseptic, skin } \\
\text { friendly and composition }\end{array}$ & 57 & 22 & 21 \\
\hline $\mathbf{7}$ & Personal experience from usage & 53 & 29 & 18 \\
\hline $\mathbf{8}$ & Motivation for the buy & 51 & 34 & 15 \\
\hline $\mathbf{9}$ & Personal Attitude & 67 & 26 & 7 \\
\hline $\mathbf{1 0}$ & Personality-Lifestyle & 54 & 36 & 10 \\
\hline $\mathbf{1 1}$ & Other's influence on buy & 21 & 20 & 59 \\
\hline $\mathbf{1 2}$ & SED aspects on buy & 49 & 41 & 10 \\
\hline
\end{tabular}

Table 2: Salient aspects moderating the purchase behavior of rural respondents of Ernakulam for FMCG Personal care items like soaps \& detergents.

\begin{tabular}{|c|l|c|c|}
\hline S.No & Influence of mass media on HH & Semi-Urban (\%) & Rural (\%) \\
\hline $\mathbf{1}$ & CTV & 100 & 100 \\
\hline $\mathbf{2}$ & Print-Newspaper/Magazines & 58 & 86 \\
\hline $\mathbf{3}$ & FM radio & 33 & 81 \\
\hline $\mathbf{4}$ & WWW/Internet portals \& Social networks & 98 & 78 \\
\hline $\mathbf{5}$ & $\begin{array}{l}\text { Exhibitions/Festival Fairs/Hoardings/ } \\
\text { Display boards }\end{array}$ & 69 & 46 \\
\hline $\mathbf{6}$ & WOM & 35 & 89 \\
\hline $\mathbf{7}$ & Direct marketing & 24 & 38 \\
\hline
\end{tabular}

Table 3: Media usage influence on rural consumers on their purchase of FMCG Personal care Goods like soaps \& detergents.

\begin{tabular}{|c|l|c|c|}
\hline S.No & Important priorities in family spending & Semi-Urban (\%) & Rural(\%) \\
\hline $\mathbf{1}$ & Money :Investments/Spending & 23 & 14 \\
\hline $\mathbf{2}$ & $\begin{array}{l}\text { Family members -general welfare \& assets } \\
\text { buildup for future; Food and happiness }\end{array}$ & 15 & 21 \\
\hline $\mathbf{3}$ & Healthcare of members & 10 & 10 \\
\hline $\mathbf{4}$ & Professional Education of Children & 16 & 19 \\
\hline $\mathbf{5}$ & Investment on Children on Assets & 11 & 15 \\
\hline $\mathbf{6}$ & Parental care/medical facilities availing & 5 & 10 \\
\hline $\mathbf{7}$ & Profession/ career enhancement & 6 & 4 \\
\hline $\mathbf{8}$ & Entertainment/relaxation /fashion/Leisure & 8 & 3 \\
\hline $\mathbf{9}$ & $\begin{array}{l}\text { Socialization/Social Club memberships/ } \\
\text { Travel/Art \& Community services }\end{array}$ & 6 & 4 \\
\hline & Total & $\mathbf{1 0 0}$ & $\mathbf{1 0 0}$ \\
\hline
\end{tabular}

Table 4: Most Priority accorded in the family on expenditure-spending.

\begin{tabular}{|c|l|c|c|}
\hline S.No & Important priorities in family spending & Semi-Urban (\%) & Rural (\%) \\
\hline $\mathbf{1}$ & Credits-Loans with EMI: Buy now pay later & 2 & 3 \\
\hline $\mathbf{2}$ & Discount Coupons & 14 & 13 \\
\hline $\mathbf{3}$ & Price-off discounts & 29 & 31 \\
\hline $\mathbf{4}$ & Freebies & 12 & 13 \\
\hline $\mathbf{5}$ & Scratch \& Win Card offers & 8 & 10 \\
\hline $\mathbf{6}$ & Lucky draw & 2 & 3 \\
\hline $\mathbf{7}$ & Extra quantity & 17 & 14 \\
\hline $\mathbf{8}$ & Gifts & 3 & 4 \\
\hline $\mathbf{9}$ & Bundling & 13 & 9 \\
\hline & Total & $\mathbf{1 0 0}$ & $\mathbf{1 0 0}$ \\
\hline
\end{tabular}

Table 5: Most effective sales promotion measures influencing purchase of FMCG items.

Consumers. Also the $\mathrm{H} 01$ and $\mathrm{H} 02$ are rejected; the consumption motive, personality-lifestyles and purchase attitude significantly influences the purchase behavior of the consumer.

H04: There is no significant difference between wife and husbands on the enablers of purchase behavior (Table 7). There exist no significant difference between Husband and wife on the impact package lustre attraction and the influence of others in influencing their purchase behavior towards FMCG Personal care items. However there exist significant difference between the husband and wife on the other variables listed above.

H05: There is no significant difference in the influence of aspects on the purchase behavior of rural and semi-urban consumers (Table 8). $\mathrm{H} 05$ is rejected for aspects like quality-value, brand liking, fragrance/ aroma, past experience, product benefits and uniqueness-visibility, and accepted for aspects like consumption frequency, other's influence, consumption motive, price affordability and packaging lustre.

The shop aspects like consistent location of items in the shop, availability of the advertised products and acceptance of coupons of lucky draws are not statistically significant Table 9. 


\begin{tabular}{|c|c|c|c|c|c|}
\hline 8 & Profile of Consumer Personal Influence & Chi-Square Value (Calc) & Table value & S/NS & Decision/Inference \\
\hline a & Age/FLC Stage & 19.616 & 9.488 & S & H03 rejected \\
\hline b & Gender & 17.753 & 7.815 & $S$ & H03 rejected \\
\hline c & Family size & 9.616 & 9.488 & S & $\mathrm{H} 03$ rejected \\
\hline d & Educational level & 17.967 & 12.592 & S & $\mathrm{H} 03$ rejected \\
\hline e & Occupation & 14.417 & 12.592 & S & $\mathrm{H} 03$ rejected \\
\hline$f$ & Disposable income to spend & 29.664 & 16.919 & S & $\mathrm{H} 03$ rejected \\
\hline g & Personality-Lifestyle & 31.9727 & 9.488 & $S$ & H01 rejected \\
\hline h & Purchase attitude & 28.802 & 9.488 & S & $\mathrm{H} 02$ rejected \\
\hline $\mathbf{i}$ & Consumption Motive & 24.334 & 16.919 & S & H01 rejected \\
\hline j & Suggestions of others/family & 2.638 & 7.815 & NS & H03 accepted \\
\hline
\end{tabular}

Table 6: Influence of SED Aspects on Consumer purchase behavior of SU-Rural.

\begin{tabular}{|c|c|c|c|c|c|c|}
\hline \multicolumn{2}{|c|}{ Enablers of purchase behavior } & \multirow{2}{*}{$\begin{array}{l}\mathbf{N} \\
56\end{array}$} & \multirow{2}{*}{$\begin{array}{c}\text { Mean } \\
2.56\end{array}$} & \multirow{2}{*}{$\begin{array}{c}\text { t-value } \\
2.663 \\
\end{array}$} & \multirow{2}{*}{$\begin{array}{c}\text { Sig.(2-tailed) } \\
0.017\end{array}$} & \multirow{2}{*}{$\begin{array}{c}\text { Remark for Null H04 } \\
\text { @.05 } \\
\text { Rejected }\end{array}$} \\
\hline Media appeal & Hus & & & & & \\
\hline & Wife & 44 & 2.25 & & & \\
\hline \multirow[t]{2}{*}{ Packaging Lustre } & Hus & 56 & 2.04 & 1.973 & 0.121 & Accepted \\
\hline & Wife & 44 & 2.34 & & & \\
\hline \multirow[t]{2}{*}{ Brand liking } & Hus & 56 & 2.52 & 2.512 & 0.022 & Rejected \\
\hline & Wife & 44 & 2.82 & & & \\
\hline \multirow[t]{2}{*}{ Value for money } & Hus & 56 & 2.73 & 2.816 & 0.009 & Rejected \\
\hline & Wife & 44 & 2.89 & & & \\
\hline \multirow[t]{2}{*}{ Retailor patronage-offers } & Hus & 56 & 2.14 & 2.608 & 0.012 & Rejected \\
\hline & Wife & 44 & 2.53 & & & \\
\hline \multirow[t]{2}{*}{ Product-specific attributes } & Hus & 56 & 2.1 & 2.518 & 0.021 & Rejected \\
\hline & Wife & 44 & 2.53 & & & \\
\hline \multirow[t]{2}{*}{ Past experience-memory } & Hus & 56 & 2.44 & 3.155 & 0.001 & Rejected \\
\hline & Wife & 44 & 2.01 & & & \\
\hline \multirow[t]{2}{*}{ Consumption motive } & Hus & 56 & 2.5 & 2.496 & 0.029 & Rejected \\
\hline & Wife & 44 & 2.1 & & & \\
\hline \multirow[t]{2}{*}{ Consumption attitude } & Hus & 56 & 2.02 & 2.437 & 0.042 & Rejected \\
\hline & Wife & 44 & 2.45 & & & \\
\hline \multirow[t]{2}{*}{ Personality-Lifestyle } & Hus & 56 & 2.28 & 3.044 & 0.004 & Rejected \\
\hline & Wife & 44 & 2.78 & & & \\
\hline \multirow[t]{2}{*}{ Other's influence/SN } & Hus & 56 & 1.93 & 1.068 & 0.288 & Accepted \\
\hline & Wife & 44 & 1.77 & & & \\
\hline \multirow[t]{2}{*}{ Specific SED aspects } & Hus & 56 & 1.57 & 2.453 & 0.033 & Rejected \\
\hline & Wife & 44 & 2 & & & \\
\hline \multirow[t]{2}{*}{ Purchase decision style } & Hus & 56 & 2.68 & 3.048 & 0.003 & Rejected \\
\hline & Wife & 44 & 2.32 & & & \\
\hline
\end{tabular}

Table 7: T test on influence of purchase behavior of SU/Rural HH: Contrast of Husband and wife on various influencing aspects of FMCG-Personal care products

From above Figure 1 and Table 10, consumers are more quality and price oriented. Also they are conscious about the brand image. Fragrance and packaging are least influencing attributes on the respondents.

From above Figure 2 and Table 11, Consumers are more quality and price oriented. Also they are conscious about the brand image. Fragrance and packaging also play important role for purchasing detergent powder.

From the above graphs (Figure 3) and Table 12, on the salient attributes for soaps and detergent, quality is the most influencing attribute in the purchase, while price is also an important attribute driving the purchase behavior.

\section{Findings and Recommendations}

The Study on FMCG products like soaps and detergents shows that the rural \& suburban consumers are more concerned about the quality, brand name and brand benefits of the personal care products purchased by them. Further it was also found that once the rural consumers found that certain brands are suitable to their, they do not change it easily due to influence of friends/social group and lack of availability of their usual brands. In case of non-availability of their personal care brand at the store where they purchase regularly, they often go to another retail store to get their preferred brand and do not compromise easily. SED Variables, motive, attitude and store attributes apart from the product attributes significantly influences the rural and semi-urban consumer behavior towards FMCG.

Local retailers were found to play a vital role, especially when the respondents are illiterate. These store keepers introduce and inform them about the brand, its benefits and also about the promotional offers. Hence the marketer has to develop a good rapport with the local retailers to reach the illiterate rural consumers. Support and cooperation from local retailers also helps in getting a competitive edge over local brands sold in rural areas. Friends/Social group were found to have considerable influence on respondents who were single, as they involve in brand discussions to decide their purchase. 
Citation: Kumar NA, Joseph J (2014) A Study on Consumer Behavior towards Fmcg Products among the Rural-Suburban Hhs of Ernakulam. J Glob Econ 2: 127. doi:10.4172/2375-4389.1000127

Page 7 of 10

\begin{tabular}{|c|c|c|c|c|c|c|}
\hline & & Sum of Squares & Mean Square & F Value & Sig. & Remark for H05 @.05 \\
\hline \multirow{3}{*}{ Quality-Value } & Between Groups & 11.08 & 2.216 & $5.933^{* *}$ & 0 & Rejected \\
\hline & Within Groups & 35.11 & 0.374 & & & \\
\hline & Total & 46.19 & & & & \\
\hline \multirow{3}{*}{ Packaging Lustre } & Between Groups & 2.363 & 0.788 & 1.31 & 0.28 & Accepted \\
\hline & Within Groups & 57.747 & 0.602 & & & \\
\hline & Total & 60.11 & & & & \\
\hline \multirow{3}{*}{ Branding } & Between Groups & 5.831 & 1.166 & 2.371 & 0.05 & Rejected \\
\hline & Within Groups & 46.209 & 0.492 & & & \\
\hline & Total & 52.04 & & & & \\
\hline \multirow{3}{*}{ Fragrance/Aroma } & Between Groups & 1,937 & 0.646 & $3.858^{* *}$ & 0.01 & Rejected \\
\hline & Within Groups & 16,063 & 0.167 & & & \\
\hline & Total & 18 & & & & \\
\hline \multirow{3}{*}{ Price affordability } & Between Groups & 0.163 & 0.054 & 0.112 & 0.95 & Accepted \\
\hline & Within Groups & 46.597 & 0.485 & & & \\
\hline & Total & 46.76 & & & & \\
\hline \multirow{3}{*}{ Past experience } & Between Groups & 10.347 & 3.449 & $4.417^{* *}$ & 0.01 & Rejected \\
\hline & Within Groups & 74.963 & 0.781 & & & \\
\hline & Total & 85.31 & & & & \\
\hline \multirow{3}{*}{ Consumption-motive } & Between Groups & 1.387 & 0.462 & 0.99 & 0.4 & Accepted \\
\hline & Within Groups & 44.803 & 0.467 & & & \\
\hline & Total & 46.19 & & & & \\
\hline \multirow{3}{*}{ Other's influence } & Between Groups & 0.03 & 0.177 & 0.597 & 0.62 & Accepted \\
\hline & Within Groups & 28.43 & 0.296 & & & \\
\hline & Total & 28.96 & & & & \\
\hline \multirow{3}{*}{ Product benefits } & Between Groups & 3.59 & 1.368 & 2.413 & 0.04 & Rejected \\
\hline & Within Groups & 53.271 & 0.567 & & & \\
\hline & Total & 60.11 & & & & \\
\hline \multirow{3}{*}{ Consumption-frequency } & Between Groups & 2.397 & 0.799 & 2.1 & 0.11 & Accepted \\
\hline & Within Groups & 36.513 & 0.38 & & & \\
\hline & Total & 38.91 & & & & \\
\hline \multirow{3}{*}{ Uniqueness-Visibility } & Between Groups & 6.67 & 2.223 & $4.704^{* *}$ & 0 & Rejected \\
\hline & Within Groups & 45.37 & 0.473 & & & \\
\hline & Total & 52.04 & & & & \\
\hline
\end{tabular}

Table 8: Summary of 1w ANOVA on aspects influencing purchase behavior of rural and semi-urban respondents for FMCG-personal care product attributes.

\begin{tabular}{|c|c|c|c|c|c|}
\hline \multicolumn{6}{|c|}{ T-test for Retail shop aspects influencing the purchase behavior of Consumers } \\
\hline S.No. & Store Attributes preferred & Mean & Standard Deviation & $\mathbf{t}$ & Sig.@P<.05 \\
\hline 1 & Consistent location of items for ease of finding items & 12.6448 & 3.80692 & -0.413 & 0.68 \\
\hline 4 & Availability of advertised products & 12.5956 & 3.65279 & -0.688 & 0.492 \\
\hline 5 & Easy to read signs/price stickers & 13.276 & 3.60332 & 2.914 & 0.004 \\
\hline 6 & Helpful cashiers, baggers, other store personnel & 13.1038 & 3.45383 & 2.087 & 0.038 \\
\hline 8 & Help in finding items in store & 12.276 & 3.50855 & -2.46 & 0.014 \\
\hline 9 & Placement of items on lower shelves for ease of reach & 11.8852 & 3.94037 & -4.087 & 0 \\
\hline 10 & Personal items suited to my need & 11.8689 & 3.59364 & -4.569 & 0 \\
\hline 11 & Packaging/ sizes suited to my age/household needs & 12.2268 & 3.67821 & -2.602 & 0.01 \\
\hline 12 & Quality of products & 13.2404 & 3.31491 & 2.963 & 0.003 \\
\hline 13 & Attractive prices for products & 13.8169 & 3.37547 & 6.177 & 0 \\
\hline 14 & Store reputation and location & 13.1913 & 3.4872 & 2.547 & 0.011 \\
\hline 15 & Accepts coupons from Lucky draws & 12.6284 & 3.67348 & -0.514 & 0.608 \\
\hline 17 & Option to return items for replacements & 13.194 & 3.50547 & 2.548 & 0.01 \\
\hline
\end{tabular}

Table 9: Shop attributes significant for the SU-Rural Consumers preferred choice.

Package factor has considerable influence on younger respondents as they prefer attractive package colors and design, while illiterates often identify their brand with the color of the package rather than the brand name. FMCG are such a market where the level of loyalty remains low and this is because of many reasons. Quality is the most influencing factor in the purchase decision while price is also an important for purchase decision. Schemes always attract more and more consumers towards particular brand. Simultaneously it gives idea about the factors which consumers look most in the product before they make final decision. Price off and extra quantity is the two main offers/schemes which consumers have come across at the time of purchase. CTV is the best mass media to market the product which will cover majority of the rural/semi-urban viewer ship for the masses. On the second place it shows newspaper as the media to promote the product in the market. People are not much aware of the schemes which continue in the market it may be because of the present stock of the product at 


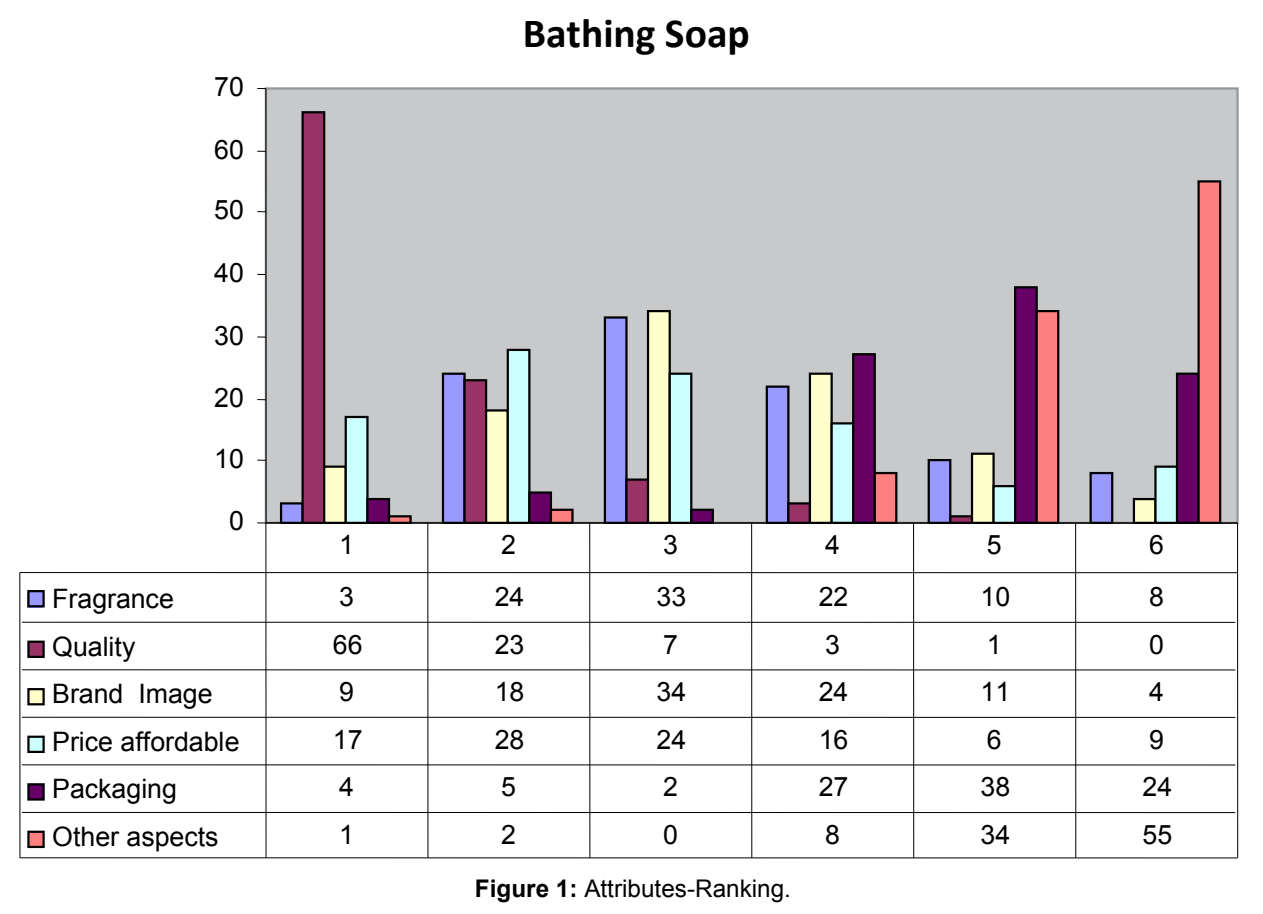

\begin{tabular}{|c|c|c|c|c|c|c|}
\hline \multirow{2}{*}{ Soap Attributes Ranking } & YARDLY & PEARS & LUX & CINTHOL & REXONA & HAMAM \\
\hline & 1 & 2 & 3 & 4 & 5 & 6 \\
\hline Fragrance & 3 & 24 & 33 & 22 & 10 & 8 \\
\hline Quality & 66 & 23 & 7 & 3 & 1 & 0 \\
\hline Brand Image & 9 & 18 & 34 & 24 & 11 & 4 \\
\hline Price affordability & 17 & 28 & 24 & 16 & 6 & 9 \\
\hline Packaging & 4 & 5 & 2 & 27 & 38 & 24 \\
\hline Other aspects & 1 & 2 & 0 & 8 & 34 & 55 \\
\hline
\end{tabular}

Table 10: Ranking of attributes in the purchase of leading Bathing Soap Brands.

\section{Detergent}

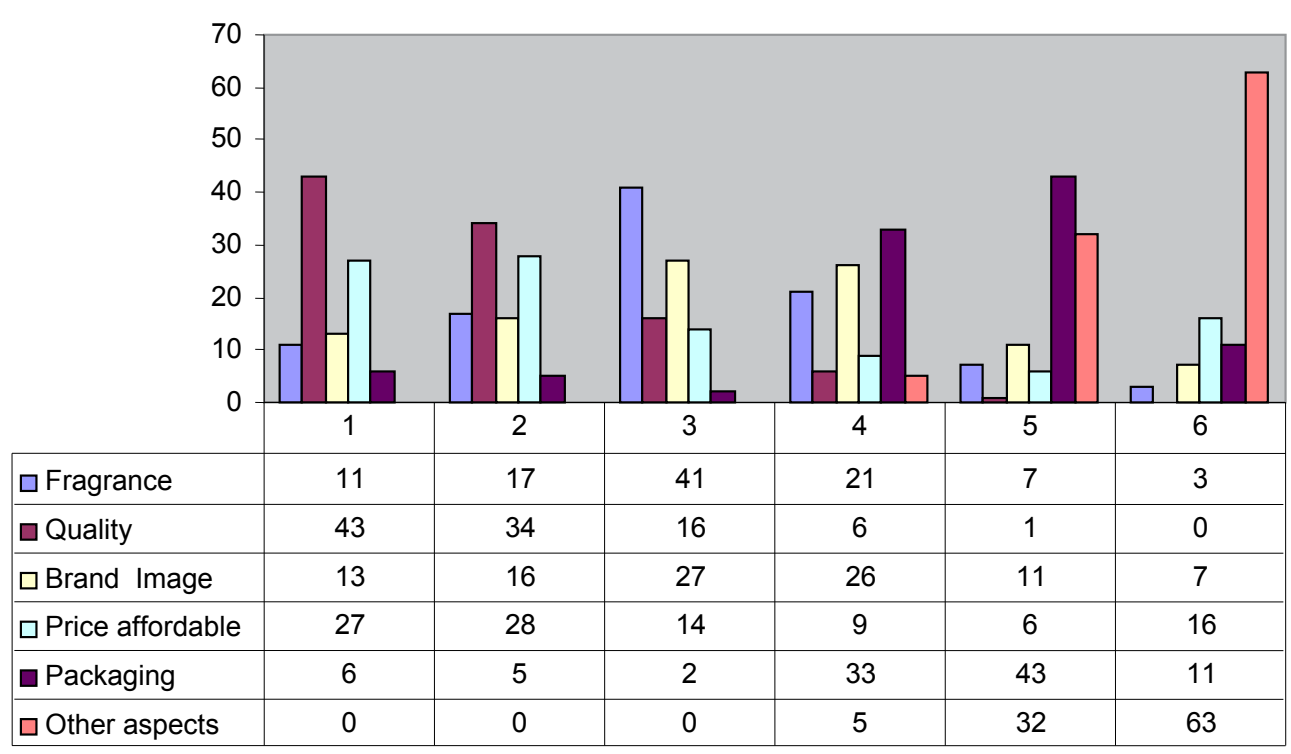

Figure 2: Attributes-Rank (1=Best and 6=Least preferred), Max count=100 nos. 


\begin{tabular}{|c|c|c|c|c|c|c|}
\hline DETERGENT & SURF & SUNLIGHT & UJALA & HENKO & RIN & WHEEL \\
\hline Attributes ranking \& No. & 1 & 2 & 3 & 4 & 5 & 6 \\
\hline Fragrance & 11 & 17 & 41 & 21 & 7 & 3 \\
\hline Quality & 43 & 34 & 16 & 6 & 1 & 0 \\
\hline Brand Image & 13 & 16 & 27 & 26 & 11 & 7 \\
\hline Price affordable & 27 & 28 & 14 & 9 & 6 & 16 \\
\hline Packaging & 6 & 5 & 2 & 33 & 43 & 11 \\
\hline Other aspects & 0 & 0 & 0 & 5 & 32 & 63 \\
\hline
\end{tabular}

Table 11: Attributes on Detergent brands.

\section{Attributes influencing purchase behavior}

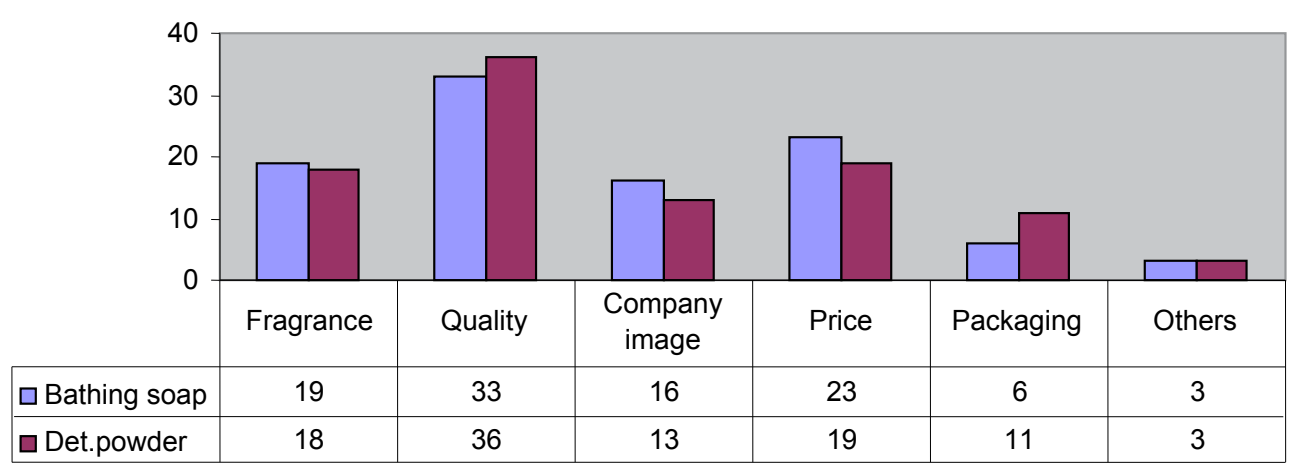

Figure 3: Salient attributes.

\begin{tabular}{|c|c|c|}
\hline Attributes (No.)/100 & Bathing soap & Deterg. Powder \\
\hline Fragrance & 19 & 18 \\
\hline Quality & 33 & 36 \\
\hline Company image & 16 & 13 \\
\hline Price & 23 & 19 \\
\hline Packaging & 6 & 11 \\
\hline Others & 3 & \\
\hline
\end{tabular}

Table 12: Salient attributes chosen in the purchase of Bathing Soaps / Detergents.

their place. $1+1$ or $2+1$ or other free schemes are more demanded and more aware schemes in the market. People are ready to switch over to another brand if they find better promotional schemes which suits their budget means more quantity, less cost and high quality. Extra quantity with less or same price, more satisfaction, quality and other factors influence consumers to switch over too other brands. Retailer stocks all types of soap and detergent because of competition. People are more quality and price oriented. Consumers remember that name of the product by the company name and also from the past performance of that company. Consumer remembers that name of the product by the company name and also from the past performance of that company. Marketer to provide better relationship with consumers and provide quality product through brand positioning. Sales promotions like Price off, product bundling and extra quantity are more demanded by the consumers over others schemes. There exist significant difference between the rural and sub-urban consumers on attributes like qualityvalue, brand liking, fragrance/aroma, past experience, product benefits and uniqueness-visibility, and no significant difference for attributes like consumption frequency, other's (normative) influence, consumption motive, price affordability and packaging lustre.

\section{Limitations of the Study}

The sample size is only 100, which is not very large. All the respondents could be accessed only through Interview, problem of time and lack of positive behavior evidenced. Respondent could have provided biased answer due to lack of information on product brands. The findings of the study are based on the assumption that the respondents have given correct information in a cognitive manner befitting the application of TPB.

\section{Conclusion}

Several leading brands of bathing soaps and detergents are prevailing in the market at Ernakulam and promoted by leading manufacturers like HUL, P\&G, Godrej, Ujala Laboratories etc. This study focused on gaining insight into the influence of various factors on the purchase behavior of rural/semi urban consumers. The factors included were related to the personal care brands on bathing soaps and detergents. From the study it is evident that quality of personal care brands were given more emphasis and the difference in educational level of respondents is significant in case of certain factors namely quality, pricing and the retailer. With increased education the rational thinking of rural consumers improved, impulse buying can be reduced. Kerala is well known for literacy. The educated consumers make more rational decisions even though they belong to the rural regions. Income had a significant difference across Marital Status and Gender of respondents in influencing their purchase decision. Majority of 
the consumers did not mind visiting towns/city to purchase good quality brands of Personal care products. Further, the marketers must constantly monitor the rural consumer purchase behavior through local retailers and seek their assistance in curbing fake local brands. The findings of the empirical study indicate that unless the brand to be promoted is in the consideration set of the consumer, sales promotion by itself is unlikely to have any major impact. Clearly this shows that marketers need to invest into brand building exercise so that his/her brand appears in the consideration set of the target consumers and then on the sales promotion activities. Sales promotion should not be used in isolation but needs to be integrated with other tools and in line with the overall positioning of the brand. Also the importance of the role of mass media came out clearly in the study. Companies need to create sufficient aw areness about sales promotion schemes through mass media in order to create awareness among rural consumers. FMCG products are low involvement products characterized by brand switching behavior from consumers. Also the consumer visiting the shop for the purchase of soap/detergent is the final decision maker of the brand. Hence it is essential that companies need to design attractive, striking, visible POPs for scheme announcements. With respect to nature of scheme, the finding suggested that premium (free gift) was most popular with companies, while both retailers and consumers preferred price offs. Hence, it is necessary that the perceived value of a free gift shall be appealingly high for the target consumers. Repetitive use of the same premium product for a prolonged period may have negative effect on the brand loyal consumers. When the company is giving its own product free as premium, it needs to ensure the quality of the product from it as it is likely to jeopardize the image of both its products. The findings exhibited that both the retailers and consumers perceived that sales promotion activities carried out by the companies were for increasing sales in short term and clearing excess stocks. What this implies is that companies need to use sales promotion synergistically and communicate so that they provide value to the target audience and enhance brand quality/image perceptions. Companies need to systematize information flow regarding sales promotion activities particularly at dealer and retailer level. Ensuring proper information flow and devising checks and measures to reduce misappropriations and implementation flows should be considered critical aspects for the success of sales promotion activities by the companies. As retailing is fragmented, direct reach by companies is not feasible. Through dealers and proper feedback mechanism, companies can keep track of the market. From the study it was found that smaller retailers felt neglected and not enthused to implement the schemes, particularly when additional handling, stocking, accounting was required on the part of a retailer without compensatory margins. It can be seen that the retailer and consumer perceptions matched with respect to preferences of schemes, underlying motivations and role of mass media. This implies that the retailer would be a rich source of information about the consumer and the likely response to sales promotion activities. Developing a system to tap such responses from time to time both at retailer and consumer level would be helpful for planning future sales promotion activities. In order to build trust and commitment companies should tap preferences, perceptions of retailers as well as consumers through relationship marketing, and herald online shopping from home.

\section{References}

1. Garga P, Ghuman K, Dogra B (2009) Rural marketing of select Fast Moving Consumer Goods in Punjab. Indian J Market 39: 21-27.

2. Selvaraj A (2007) Rural Consumer's behaviour regarding Non-Durable goods A study in Erode district of Tamil Nadu. Indian J Market 37: 35-39.

3. Anandan C, Raj MSM, Madhu S (2007) A study on brand preference of washing soaps in rural areas. Indian J Market 37: 30-37.

4. Madhavi C, Kumar SA (2006) Rural Marketing 34: 30-35

5. Nagaraja (2004) Consumer Behavior in rural areas: A micro level study on buying behavior of rural consumers in Kaval Mandal. Indian J Market 34: 30-35.

6. Belch MA, Willis LA (2002) Family decision at the turn of the century: Has the changing structure of Households impacted the family decision making process. J Consum Behav 2: 111-124.

7. Bijapurkar R, Ravi M (1999) Rural markets for consumer durables, The Economic Times.

8. The Marketing White book (2011) Business world.

9. Krishnamacharyulu CSG, Ramachandran L (2008) Rural marketing-Text and Cases, Pearson Education Asia.

10. Gopalaswamy TP (1997) Rural Marketing, Wheeler Publishing House New Delhi.

11. Kashyap P, Siddhartha R (2008) The Rural Marketing Book. Biztantra.

12. ORG-MARG Rural Consumers (2010) Survey reports.

13. Kotler P (2005) Marketing Management. Prentice Hall of India, Delhi.

14. Kanuk S (2008) Consumer Behavior. Prentice Hall of India, Delhi. 